DOI: $10.17805 /$ zpu.2018.1.5

\title{
Идеологическая функция культурной политики
}

\author{
А. Я. ФЛИЕР
}

РОССИЙСКИЙ НАУЧНО-ИССЛЕДОВАТЕЛЬСКИЙ ИНСТИТУТ КУЛЬТУРНОГО И ПРИРОДНОГО НАСЛЕДИЯ ИМ. Д. С. ЛИХАЧЕВА

В статье излагается авторский взгляд на основные цели и задачи культурной политики. Научная новизна статьи в том, что основные ее положения еще не высказывались в научной литературе с такой определенностью и четкостью. Актуальность статьи заключается в возможности использования ее положений в практике управления культурой и ее регулирования.

Основная цель культурной политики, по мнению автора, состоит во внедрении в массовое сознание господствующей идеологии, причем в наиболее мягкой, ненасильственной форме. Господствующая идеология в современной России - это этатизм (государствоцентризм), реализуемый в сравнительно умеренной форме политической практики. В рамках этой идеологии главная задача культурной политики - обеспечить лояльность большинства населения к власти и ее политической программе.

Население может быть аналитически разделено на четыре группы: активно лояльных, пассивно лояльных, фальшиво лояльных и нелояльных граждан. Основными адресатами культурной политики являются пассивно лояльные люди, которых нужно склонить к электоральной активности и поддержке действующей власти. Главным инструментом воздействия на сознание людей в рамках культурной политики выступают искусство и литература. При этом особый акцент делается на активизацию исторической памяти и чувства патриотизма.

Такая культурная политика не является изобретением нашего времени, а известна из глубин истории, со времен появления первых государств.

Ключевые слова: культура; культурная политика; государственная идеология; политическая лояльность; электоральное поведение; патернализм

\section{ВВЕАЕНИЕ}

$\mathrm{T}$ ематике культурной политики посвящено много научных исследований. В этой проблеме научный приоритет я отдаю О. Н. Астафьевой (см., например: Астафьева, 2006, 2010a, 2010b и др.), которую считаю наиболее интересным теоретиком, и в основном соглашаюсь с ее сентенциями. Тем не менее я позволю себе высказать и некоторые собственные соображения на этот счет.

Культурная политика в России, осуществляемая в первую очередь Министерством культуры РФ (хотя и не только им), преследует много разных целей - разви- 
тие искусства, охрану культурного наследия, организацию культурного досуга, развитие культуры и гуманитарной әрудиции населения и пр. Раньше в систему отрасли культуры входили еще и СМИ (что, на мой взгляд, было вполне логичным по общности целей), но сейчас они отданы в ведение Министерства связи и массовых коммуникаций РФ.

Следует отметить, что государственная отрасль культуры и феномен культуры в научном понимании - понятия далеко не тождественные, а лишь соприкасающиеся. Государственная отрасль культуры регулирует в основном досуговое времяпрепровождение людей (чтение книг, посещение кино, театров, парков, музеев и выставок, клубные занятия, художественную самодеятельность и пр.), а культура в научном понимании - это в первую очередь система обычаев и языков социального взаимодействия. Но здесь речь идет именно об отрасли культуры, руководимой соответствующим министерством.

\section{ИАЕОАОГИЯ КАК ЦЕАЬ КУАЬТУРНОЙ ПОАИТИКИ}

Среди многообразия целей культурной политики, по моему мнению, выделяется одна цель, являющаяся наиважнейшей. Это внедрение государственной идеологии в массовое сознание населения. Я полагаю культурную политику одним из главных инструментов такого внедрения, причем осуществляет она это наиболее мягким, ненасильственным способом. Конечно, государственная идеология запрещена Конституцией Российской Федерации, но это только декларация. Ни одно государственное образование не в состоянии обходиться без идеологии, и фактически запрещено лишь преследование людей, придерживающихся иной идеологии. Сама идеология является специфической мифологией власти, а власть не может нормально функционировать без мифа о себе. Такова природа власти (см. об этом: Бочаров, 2006).

Современная государственная идеология России может быть определена как этатизм, с характерной для него абсолютизацией эффективности государственной машины ( «вертикали власти»), приоритетом государства и политической власти над обществом с его общественным самоуправлением и т. п. Этатизм - это одно из направлений консерватизма, опирающееся на приоритет не этнического (как в национализме) и не религиозного (как в клерикализме), а именно политического начала, на идею государства (от фр. État - государство) как наиболее эффективной формы социальной организации по сравнению с иными формами (этносом, классом, конфессией). Отсюда и такая неприязнь власти к либерализму, отстаивающему диаметрально противоположную идею о приоритете гражданского общества над государством и ограничении государственных полномочий только правом применять насилие. Российская культурная политика, естественно, тоже стоит на позициях этатизма, т. е. государствоцентризма.

Традиция этатизма в России очень давняя. Если в средневековой Руси еще имела место борьба между самодержавием и вечевым управлением и сакрализовывалась в основном личность правителя (князя, хана, царя), то начиная с Петра Великого в государственную идеологию стала жестко внедряться идея сакрализации самого института государства как высшей ценности национального существования. Эта идея оставалась актуальной в Российской империи в XVIII-XIX вв., при советской власти в XX в., сохраняет свою системообразующую роль в пост- 
советской России в XXI в. и, как представляется, будет торжествовать в стране еще долго. С этим связаны и определенные черты национальной ментальности россиян, культ государственного служения, повышенная склонность к патернализму, ожидание реальных благ только от государства, ощущение себя маленькими детьми под присмотром строгого воспитателя - государства и т. п. Говорить о какой-либо демократии и общественном самоуправлении в этих условиях не приходится.

Разумеется, этатизм, как и любая иная политическая программа, может быть разным по своим практическим политическим формам. Наиболее жесткая форма этатизма нам известна на примере Италии 1920-х - первой половины 1940-х годов. Гораздо более умеренным был этатизм в Испании второй половины 1930-х - первой половины 1970-х годов. Современный российский этатизм имеет много общего с испанским вариантом, точно так же акцентировано апеллирует к религии и патриотизму, избегает массового насилия и расизма, воплощается в основном в государственном контроле над информацией и культурой, в декларативной консервативной идеологии.

Смысл и цель любой государственной идеологии я нахожу в поддержании максимальной лояльности населения по отношению к действующей власти. Такая лояльность включает и социальный, и национальный, и религиозный аспекты, но, конечно, основной является политическая лояльность, которая внедряется в сознание граждан всеми доступными способами.

Таких способов я насчитываю четыре:

- разного рода политические мероприятия, разжигающие лоялистский ажиотаж в массах;

- усилия контролируемых государством СМИ, направленные на то же самое;

- репрессии против нелояльных граждан (массовые или точечные);

- культурная политика как наиболее мягкая форма влияния, внедряющая лояльность в массовое сознание преимущественно средствами искусства, в процессах воспитания и образования, на разных досуговых мероприятиях и т. п.

Таким образом, культурная политика так или иначе связана с государственной идеологией и работает на ее интересы независимо от того, насколько это понимают люди, непосредственно занимающиеся культурной политикой, и тем более люди, на сознание которых направлена эта политика. Задача поддержания политической лояльности среди населения решалась много проще в историческом прошлом, когда основным источником информации для людей была проповедь приходского священника, а для грамотных горожан - газеты. Альтернативой этому выступали лишь соседские сплетни. Ныне, когда альтернативные источники информации легко доступны во множестве, задача внедрения государственной идеологии в массовое сознание существенно усложнилась.

Вместе с тем было бы ошибочным сводить все функции культурной политики лишь к обслуживанию государственной идеологии. Конечно же, она решает и множество других задач по регулированию социальной жизни, является одной из форм просветительства и пр. (см. об этом, например: Разлогов, Орлова, Кузьмин, 2005: Электронный ресурс; Востряков, 2011; Гавров, 2013 и др.). Но представляется, что по своей политической значимости все они уступают задачам обеспечения государственной идеологии. 


\section{НАПРАВАЕНИЯ КУАЬТУРНОЙ ПОАИТИКИ}

\section{И ЕЕ АДРЕСАТ}

В целом в государственной культурной политике можно отметить следующие направления:

- поддержка развития искусства всех видов: классическое искусство (изобразительное искусство, музыка и музыкальный театр, драматический театр, балет), народное искусство и фольклор, массовое искусство (эстрада, цирк, кинематограф);

- сохранение, реставрация и экспонирование памятников истории и культурного наследия (включая музейные экспозиции);

- развитие библиотечного и архивного дела;

- развитие форм организованного досуга (в клубной и иной форме);

- развитие туризма;

- развитие гуманитарной эрудиции населения, его гражданского сознания, патриотизма и его политической лояльности.

Собственно, последний пункт, не выделенный ни в каких минкультовских структурах и программах, и является внедрением идеологии в сознание населения в наиболее прямом смысле, и это, на мой взгляд, - самая важная политическая задача, стоящая перед отраслью культуры.

На кого обращена культурная политика? Аля выявления ее адресата нужно проделать некоторую аналитическую работу. Я полагаю, что по своему отношению к власти население может быть разделено на четыре группы:

1) люди активно лояльные, в основном разделяющие взгляды и оценки власти;

2) пассивно лояльные, по существу, равнодушные, не напрягающие свое сознание самостоятельной оценкой каких-либо проблем, камуфлирующие свое безразличие сентенциями типа «начальству виднее», «власть всегда права» и т. п.;

3) фальшиво лояльные, демонстрирующие свою лояльность неискренне, а из страха перед возможными неприятностями или из прагматического расчета, что так выгоднее;

4) нелояльные к власти по тем или иным причинам (они далеко не всегда являются активными оппозиционерами, но власть не любят и не поддерживают).

Значительная часть населения современной России - это, несомненно, люди активно лояльные (что подтверждается множеством социологических исследований), и это связано не только с актуальной поддержкой населением власти и ее политики, но в первую очередь с исторической традицией патернализма, укоренившейся в народном сознании. Они доверяют власти больше, чем любым иным структурам. Но, разумеется, среди населения есть представители всех групп политической ориентации.

Представляется, что люди из первой и третьей групп (активные и фальшивые лоялисты) фактически не нуждаются в какой-либо коррекции своей позиции, а людей из четвертой группы (антилоялистов) никакая культурная политика не стимулирует к перемене их оппозиционных взглядов. Поэтому объектом воспитательноидеологического воздействия культурной политики в основном являются люди из второй группы - пассивно лояльные, т. е. не имеющие никакой осмысленной политической позиции, а поддерживающие власть в основном тем, что равнодушны к любым ее действиям и не возражают против любых ее телодвижений. 
В советском прошлом не стояла задача как-либо влиять на политическое поведение таких людей (оно регулировалось преимущественно страхом перед возможным наказанием за недостаточную активность), а воспитательное воздействие на них являлось частью общего идеологического прессинга. В наше время ситуация переменилась.

Целью воспитательно-идеологического воздействия на людей этой группы стала активизация их электорального поведения, стимуляция их к приходу на выборы и голосованию. Сами они политически пассивны и на выборы стараются не ходить; их нужно к этому подталкивать, в том числе идейно. Кроме того, люди пассивно лояльные не являются убежденными сторонниками власти и могут неожиданно поменять свой выбор под влиянием каких-то сиюминутных причин. На них нужно все время давить средствами СМИ и культурной политики.

\section{ИНСТРУМЕНТАРИЙ КУАБТУРНОЙ ПОАИТИКИ}

Естественно, возникает вопрос о средствах и инструментарии такого воспитательно-идеологического влияния культурной политики на массовое сознание. Понятно, что основными инструментами воздействия выступают произведения искусства и литературы, а в последние десятилетия главными воспитателями являются преимущественно кинофильмы «правильной» направленности. В них демонстрируются положительные примеры культурных героев, лояльность которых сюжетно вознаграждается, а нелояльность злодеев наказывается.

В отличие от СМИ, старающихся прямо и примитивно влиять на политическое поведение современного человека, культурная политика стремится производить такое воздействие более закамуфлированно. Влияние осуществляется преимущественно через стимулирование ажиотажного отношения к отечественной истории, которая в заказываемых произведениях подается как исключительно великая, описывает наших предков всегда и во всем правыми, не совершавшими никаких ошибок и злодеяний, а высших руководителей государства - просто святыми и т. п.

Особенно последовательно эксплуатируется тема подвига советского народа в Великой Отечественной войне. Тематика этой войны и победы, похоже, стала главной начиональной скрепой сегодняшних россиян, основой их идентичности. Русские уже не столько русские, сколько победители Германии. И все время присутствует намек на то, что наши современники должны равняться на отцов и дедов, штурмовавших Берлин, и совершить свой гражданский подвиг - прийти на избирательные участки и проголосовать за действующую власть, которая и есть прямая наследница «героев-панфиловцев». Такое паразитирование на истории не является новым изобретением. Все авторитарные и тоталитарные режимы XIX-XX вв. в той или иной мере опирались на это.

Как ни парадоксально, но профессиональные историки по своим идеологическим взглядам в основном прогрессисть, понимающие неповторимость истории и бессмысленность существования с «головой, повернутой назад», в историческое прошлое. Консерваторы же, наоборот, как правило, не являются профессиональными историками и всячески эксплуатируют идею повторения прошлого. Собственно, это и есть консерватизм в самом прямом смысле - вера в то, что повторение вчерашнего есть наилучший вариант будущего. Этот консерватизм является прин- 
ципиальной политической позицией власти и воспевается сегодняшней культурной политикой России.

В свое время А. С. Пушкин писал, что правительство все еще единственный европеец в России (Пушкин, 1962), т. е. власть в своих взглядах более прогрессивна, чем малограмотное население. Эта традиция тоже шла от Петра Великого. Сейчас положение принципиально иное. Власть в своих взглядах отражает консерватизм сознания значительной части населения, причем ориентируется в основном на наиболее малообразованные и малокультурные слои. Это уже традиция советских времен, идущая от Сталина.

Еще раз подчеркиваю, что не следует сводить все цели культурной политики только к отражению политической позиции власти, но и забывать об этой важнейшей задаче отрасли культуры не стоит.

\section{ЗАКАЮЧЕНИЕ}

Впрочем, подобная культурная политика зародилась еще в глубокой древности, практически с возникновением самого феномена государства. Вместе с государством родилась и идеология как мифология власти. Тогда же появились и средства внедрения этой идеологии в сознание масс, среди которых наряду с грубым насилием была и мягкая культурная политика. В течение всего аграрного периода истории основным инструментом реализации культурной политики была церковь (или иные религиозные структуры, выполнявшие ту же роль), поскольку религия в то время была одновременно и политической идеологией, а монарх был фигурой сакральной. Это особенно наглядно проявлялось в христианском и исламском ареалах, но и в буддийском, индуистском, даосистском, синтоистском и пр. было, по существу, то же самое.

В Новое время в процессе секуляризации политической власти происходила секуляризация политической идеологии и, естественно, появилась собственно культурная политика, апеллировавшая преимущественно к искусству, которое в определенном смысле стало заменой религии и начало влиять на массы больше, чем религия. Всеобщая грамотность создала определенный массовый культ книги, которым власть продуктивно воспользовалась в своих интересах. Сейчас культ книги постепенно вытесняется культом телевизора, и идеологическая активность власти переместилась на эту площадку. Но апелляция к авторитету истории была частью идеологии всегда. Это определенного рода культурная универсалия.

Столь же универсальной во все времена была и основная цель культурной политики - обеспечение политической лояльности. Просто в разные исторические эпохи лояльность выражалась по-разному. В европейской Античности и на Востоке лояльность выражалась в основном в верности традициям и обычаям, в средневековом христианском и исламском мире - в верности господствующей религии, в европейском Новом времени - в верности светской власти. Во всяком случае, наиболее жестокие наказания ожидали людей, нарушавших именно эти нормы в соответствующее время (подробнее см.: Флиер, 2014, 2015: Электронный ресурс).

В современных условиях (в частности, российских) успешность культурной политики обеспечивается ее согласованностью с информационной политикой подконтрольных власти СМИ. Культурная политика убеждает нас в нашем историче- 
ском величии, а информационная политика - в сегодняшнем военно-политическом величии. Аазейки для сомнений не остается...

Таким образом, культурная политика есть плоть от плоти государственной идеологии и является одним из инструментов ее внедрения в массовое сознание. В России эта задача облегчается патерналистскими склонностями населения, его верой в государство как наивысшую ценность, отношением к государству как к главному источнику всех благ и пр. Успешность культурной политики измеряется главным образом масштабом лояльности основной массы населения к власти. Понятно, что эта лояльность в первую очередь зависит от приемлемости экономического положения и уровня жизни населения. Но и идеологическое управление психикой и сознанием людей, так называемый социальный контроль может быть очень эффективным инструментом, и культурная политика является одним из средств такого воздействия.

\section{СПИСОК АИТЕРАТУРЫ}

Астафьева, О. Н. (2006) Теория самоорганизации как концептуальное основание культурной политики: проблемы теоретической культурологии // Вопросы культурологии. № 12. C. 18-27.

Астафьева, О. Н. (2010а) Культурная политика: теоретическое понятие и управленческая деятельность: лекции. М. : РАГС. 69 с.

Астафьева, О. Н. (2010b) Культурная политика России: теория - реальность - перспектива // Государственная служба. № 1. С. 68-73.

Бочаров, В. В. (2006) Истоки власти // Антропология власти. Т. 1. Власть в антропологическом дискурсе. СПб. : ИзА-во СПбГУ. 491 с. С. 14-48.

Востряков, А. Е. (2011). Государственная культурная политика: понятия и модели. СПб. : РАНХиГС. 168 с.

Гавров, С. Н. (2013) Культурная политика: общественно-государственное взаимодействие, технологичность, многообразие // Современная наука: актуальные проблемы теории и практики. Серия Гуманитарные науки. № 1-2. С. 63-65.

Пушкин, А. С. (1962). Письмо П. Я. Чаадаеву от 19 октября 1836 г. // Пушкин, А. С. Полное собрание сочинений : в 10 т. М. : Государственное издательство художественной литературы. T. 10. С. 307-310.

Разлогов, К. Э., Орлова, Э. А., Кузьмин, Е. И. (2005) Российская культурная политика в контексте глобализации [Электронный ресурс]// Отечественные записки. Журнал для медленного чтения. № 4 (25). URL: http://www.strana-oz.ru/2005/4/rossiyskaya-kulturnaya-politika-v-kontekste-globalizacii (дата обращения: 18.02.2017).

Флиер, А. Я. (2014) Избранные работы по теории культуры. М. : Согласие-Артем. 560 с.

Флиер, А. Я. (2015) Аобро и зло в культурно-историческом понимании [Электронный ресурс]// Информационный портал Знание. Понимание. Умение. № 3. URL: http://www.zpu-journal.ru/e-zpu/2015/3/Flier_Good-Evil/ (дата обращения: 26.09.2015).

Аата поступления: 30.11.2017 2.

\section{THE IDEOLOGICAL FUNCTION OF CULTURAL POLICY}

\section{A. Y. FLIER}

\section{Russian Scientific Research Institute for Cultural and Natural Heritage named after D. LikHacheV}

The article gives the author's view of the main goals and objectives of cultural policy. The scientific novelty of the article is that its main provisions have not yet been expressed in scientific literature with such certainty and clarity. The relevance of the article lies in the possibility of using its provisions in the practice of culture management and its regulation. 
The main goal of cultural policy, according to the author, is to introduce the dominant ideology into the mass consciousness, and in its mildest non-violent form. The dominant ideology in modern Russia is statism (state-centrism), implemented in a relatively moderate form of political practice. Within the framework of this ideology, the main task of cultural policy is to ensure the loyalty of the majority of the population to the government and its political programme.

The population can be analytically divided into four groups: actively loyal, passively loyal, falsely loyal, and disloyal citizens. The main recipients of cultural policy are passively loyal people who need to be persuaded into electoral activity and support for the current government. The main instrument of influence on people's consciousness within the framework of cultural policy is art and literature. At the same time, special emphasis is placed on the activation of historical memory and the feeling of patriotism.

Such a cultural policy is not a modern invention, but is known from the depths of history, since the appearance of the first states.

Keywords: culture; cultural policy; state ideology; political loyalty; electoral behavior; paternalism

\section{REFERENCES}

Astaf'eva, O. N. (2006) Teoriia samoorganizatsii kak kontseptual'noe osnovanie kul'turnoi politiki: problemy teoreticheskoi kul'turologii. Voprosy kul'turologii, no. 12, pp. 18-27. (In Russ.).

Astaf'eva, O. N. (2010a) Kul'turnaia politika: teoreticheskoe poniatie i upravlencheskaia deiatel'nost': lektsii. Moscow, RAGS. 69 p. (In Russ.).

Astaf'eva, O. N. (2010b) Kul'turnaia politika Rossii: teoriia - real'nost' - perspektiva. Gosudarstvennaia sluzbba, no. 1, pp. 68-73. (In Russ.).

Bocharov, V. V. (2006) Istoki vlasti. In: Antropologiia vlasti. St. Petersburg, Izd-vo SPbGU. Vol. 1. Vlast' v antropologicheskom diskurse. 491 p. Pp. 14-48. (In Russ.).

Vostriakov, L. E. (2011). Gosudarstvennaia kul'turnaia politika: poniatiia $i$ modeli. St. Petersburg, RANKhiGS. 168 p. (In Russ.).

Gavrov, S. N. (2013) Kul'turnaia politika: obshchestvenno-gosudarstvennoe vzaimodeistvie, tekhnologichnost', mnogoobrazie. Sovremennaia nauka: aktual'nye problemy teorii $i$ praktiki. Seriia Gumanitarnye nauki, no. 1-2, pp. 63-65. (In Russ.).

Pushkin, A. S. (1962). Pis'mo P. Ia. Chaadaevu ot 19 oktiabria 1836 g. In: Pushkin, A. S. Polnoe sobranie sochinenii : in $10 \mathrm{vol}$. Moscow, Gosudarstvennoe izdatel'stvo khudozhestvennoi literatury. Vol. 10. Pp. 307-310. (In Russ.).

Razlogov, K. E., Orlova, E. A. and Kuz'min, E. I. (2005) Rossiiskaia kul'turnaia politika v kontekste globalizatsii. Otechestvennye zapiski. Zhurnal dlia medlennogo chteniia, no. 4 (25) [online] Available at: http://www.strana-oz.ru/2005/4/rossiyskaya-kulturnaya-politika-v-kontekste-globalizacii (access date: 18.02.2017). (In Russ.). Russ.).

Flier, A. Ia. (2014) Izbrannye raboty po teorii kul'tury. Moscow, Soglasie-Artem. 560 p. (In

Flier, A. Ia. (2015) Dobro i zlo v kul'turno-istoricheskom ponimanii. Informatsionnyi portal Znanie. Ponimanie. Umenie, no. 3 [online] Availbale at: http://www.zpu-journal.ru/e-zpu/2015/3/ Flier_Good-Evil/ (access date: 26.09.2015). (In Russ.).

Submission date: 30.11 .2017$.

Флиер Андрей Яковлевич - доктор философских наук, профессор, главный научный сотрудник Российского научно-исследовательского института культурного и природного наследия им. А. С. Аихачева. Адрес: 129366, Россия, г. Москва, ул. Космонавтов, д. 2. Тел.: +7 (495) 686-13-19. Эл. aspec: andrey.flier@yandex.ru

Flier Andrei Yakovlevich, Doctor of Philosophy, Professor, Chief Research Fellow, Russian Scientific Research Institute for Cultural and Natural Heritage named after D. Likhachev. Postal address: 2, Kosmonavtov St., Moscow, Russian Federation, 129366. Tel.: +7 (495) 686-13-19. E-mail: andrey.flier@yandex.ru 